gauged instead of hard points. Each hair is fastened into a capsule, which moves easily up and down a metal rod. The distance of the ends of the two stimulus hairs may thus be varied at will according to the experiment to be undertaken. The whole is fastened to a handle. It is needless to say that this instrument may be used with great ease in the investigation of every part of the body without necessitating any abnormal position, and I am not, I think, going too far in repeating that by von Frey's stimulus hair method former difficulties are surmounted.

The interest aroused of late in the investigation of skin sensation gives me hope that this short notice may direct attention to this method, the application of which will certainly not be fruitless. The arrangement of the stimulus hairs occasions some difficulty at first, but this is soon overcome by practice and more than compensated for by subsequent success. Von Frey's method has proven of great value in the treatment of diseases of the eye as also is other pathological cases.

I may add to the foregoing that when one wishes to mark certain skin-points for continued investigation ro \% nitrate of silver may be applied to the skin by means of a capillary tube the walls of which must not be too thin. Injury to the nervous end-organs can in this way scarcely be apprehended. This is as a rule von Frey's method of marking skin-points under examination. I often make use of a watery solution of methyloiolet which, as I have elsewhere mentioned (Wundt. Philos. Studien, Bd. I I p. I37), dyes living tissues well and lastingly.

In conclusion I may remark that Prof von Frey intends to publish an account of his further investigations in the course of the year.

FrIedRICH Kiesow.

LHipzig.

\title{
SUSPENSION OF THE SPATIAL CONSCIOUSNESS.
}

A recent note in this journal by Professor Hyslop on our localization in space induces me to record a somewhat similar but even more pronounced case of suspension of the power of localization. It is to be noted that the dream which in Dr. Hyslop's cases 'switched out' the ordinary date of localization was, unlike most dreams, accompanied by, perhaps caused by, hallucinations of vision, such as I have described in a recent number of the Journal of Comparative Neurology. The theory which seems to have been in the narrator's mind is that the existing mental picture forcibly displaced the memory image of the 
actual place occupied. The tactile and other sensations were not adequate to displace the vivid hallucinatory image. The question in this connection which seems of greatest interest is whether the mind, in its waking state, must (or at least always does) orientate itself, whether correctly or incorrectly. Everyone knows by unpleasant experience that the tendency to extend this orientation to correspond with the limits of our field of space-conception is very strong and, once formed, the orientation is exasperatingly persistent. I had suffered from the inconvenience of being 'turned round' in unfamiliar places for many years until a simple expedient permanently rid me of the habit. The remedy consisted in charging the mind to suspend judgment of direction until an intelligent one could be formed. After a short struggle this habit was formed and, although mistakes have occurred, they have been due in every case to imperfect or incorrect data and I have never been ' turned round' since.

But the instance which it is desired to record seems to show that the mind may be for a considerable time completely unorientated in both time and space. The experience referred to has occurred to me no more than three times and the period has in two cases been quite short, while in another the time was long enough to provide for a careful study of the state. It was some months after a return from a residence in Berlin lasting several months. Meanwhile the home had been removed from Cincinnati to Granville. Yet there had been a long period of quiet routine at the new home, and the unsettled feeling which an ocean journey always produces had long since worn off. I had been for some time studying dreams and had acquired the habit of collecting my thoughts and attentively observing states following the awakening. Under these circumstances I awoke near midnight from a quiet sleep without any dream content being immanent. The room was absolutely dark and quiet. I lay at ease and it dawned upon me that I had no notion of where I was. I turned over in my mind the various sleeping apartments in which I had slept. Was this the state room of a steamer? Evidently not, for there was neither noise nor jar. Was it one of the three bed roons I recalled in Cincinnati, or was it perhaps in Berlin? I could not tell. What had I been doing the day before? I had not the faintest idea. The events of one period of the past seemed as vivid and 'present' as those of any other. For some reason the sequence of events seemed gone, though many isolated occurrences were clearly recalled. I lay some time waiting for the appearance of some associated chain, but none emerged. A momentary fear that $I$ had been smitten with blindness was relieved 
by a faint glimmer from the window. I then made several slight movements but could still get no idea of the shape of the room or of the position of objects in it. The necessary link was at last afforded by a movement on the part of my companion and a few tactile coördinations without the aid of vision. The state impressed me like that of a disembodied mind, but there seems to have been no special vascular stasis at the periphery, though it is, of course, probable that some circulatory changes had occurred in the brain. Tactile sensations were as usual. It thus is evident that the mind may operate in an apparently normal way with full consciousness and yet the correlation of vestiges necessary to localization be wholly suppressed, though other spatial reproductions are unimpaired. It is also seen that the orientation does not depend on vision or any one sense, though visual elements predominate when the orientation is at last affected. As I have said, this is not an isolated case, though in the other instances some sense impression has completed the spatial rapport before the state could be calmly observed.

Denison Untverstry. C. L. Herrick.

\section{FOCAL AND MARGINAL CONSCIOUSNESS.}

There seems to exist among a large number of recent psychological writers a strange confusion of ideas respecting one of the simplest and yet most fundamental distinctions in the science. I mean that between sense content and sensation (not the content of the sensation, which is a very different thing).

The content of sense at any given time is the sum of the affectations of the lower or primary æesthesodic centres. In the visual sphere, for example, it is the totality of the immediate central reactions corresponding to the retinal excitations. We may think of them as distributed in the homologous parts of the tectum, but it is probable that we should add the effects of certain optic reflexes with their æsthesodic reactions, and not improbable that it will be necessary to include modifications or accretions due to changes in the cortical visual area; however this may be, there is as yet no sensation-only sense content. Besides the contents of the higher senses there is the whole asthesodic contingent from the cord, many of whose elements never are brought into consciousness except under exceptional conditions. Some of them are perhaps incompetent to enter sensation at all, except as a quale of some other sensation, because they have no localizable ' tag' suit- 